\title{
PREDIKSI HARGA JUAL SUKU CADANG IMPOR MESIN ROKOK DENGAN JARINGAN SYARAF TIRUAN
}

\author{
Evanita \\ Fakultas Teknik, Teknik Informatika \\ Universitas Muria Kudus \\ Email: evanita@umk.ac.id \\ Muhammad Malik Hakim \\ Fakultas Teknik, Teknik Informatika \\ Universitas Muria Kudus \\ Email: malik.hakim@umk.ac.id
}

\begin{abstract}
ABSTRAK
Industri rokok merupakan industri vital di wilayah Kabupaten Kudus, sehingga kesiapan kinerja mesin rokok yang menjadi salah satu penggerak utama pabrik rokok menjadi sangat penting. Salah satu cara untuk menjaga agar mesin rokok senantiasa siap bekerja adalah menjaga ketersediaan suku cadang mesin rokok, terutama Garniture. Permasalahan utama yang menjadi kendala adalah adanya fluktuasi biaya-biaya dan kurs mata uang, yang membuat harga Garniture menjadi fluktuatif dan membahayakan kelangsungan hidup dari perusahaan pemasok. Penelitian ini menggunakan Metode Jaringan Syaraf Tiruan untuk memprediksi harga jual Garniture ke industri rokok. Prediksi harga jual ini membuat perusahaan pemasok dan industri rokok mengetahui prediksi harga yang cukup akurat dan selanjutnya dapat melakukan antisipasi kerugian dan hal lain yang tidak diinginkan terkait dengan fluktuasi harga yang terjadi ketika dilakukan proses pembelian. Untuk memprediksi harga jual Garniture yang tidak menentu tersebut digunakan algoritma Backpropagation dari Jaringan Syaraf Tiruan. Terkait dengan proses training dan testing yang telah dilaksanakan menggunakan algoritma Backpropagation dari Jaringan Syaraf Tiruan dengan 24 inputan, 10 hidden layer, learning rate 0,1 dan 1 output, diperolehhasil yang cukup baik dengan nilai error atau MSE yang pada proses training sebesar 0,00099001 dan MSE pada proses testing sebesar 0,19113.
\end{abstract}

Kata kunci: rokok, garniture, jaringan syaraf tiruan.

\begin{abstract}
The tobacco industry is a vital industry in Kudus District, so the readiness of cigarette machines that become one of the main drivers of the cigarette factory becomes very important. One way to keep cigarette machines always ready to work is to keep spare parts of cigarette machines, overcome Garniture. The main problems being targeted are fluctuations in costs and currency exchange rates, which made Garniture prices fluctuate and jeopardize the survival of the suppliers. This research uses Artificial Neural Network Method to predict Garniture selling price to cigarette industry. The prediction of the selling price will be made by the supplier and the cigarette industry the prediction price of the price is quite accurate and can further anticipate losses and other unwanted things related to price fluctuations that occur when will the purchase process. To predict the uncertain selling price of Garniture it will be used Backpropagation algorithm of Neural Network. Related to the training and testing process that has been implemented using Backpropagation algorithm from Artificial Neural Network with 24 input, 10 hidden layers, learning rate 0,1 and 1 output, afford quite good with error or MSE which in the training process of 0.00099001 and MSE on trial process 0.19113 .
\end{abstract}

Keywords: cigarette, garniture, neural network.

\section{PENDAHULUAN}

Industri rokok di Kabupaten Kudus merupakan salah satu industri utama yang menjadi sumber penghasilan utama bagi masyarakat. Fasilitas industri rokok menempati posisi yang sangat strategis dalam peningkatan laju pertumbuhan ekonomi masyarakat. Dalam kelangsungan operasional hariannya, industri rokok beroperasi selama 24 jam untuk menghasilkan dan memenuhi hasil produksi rokok dengan standar kualitas dan target kuantitas tertentu. Sebagai industri yang sangat vital tersebut, operasional dari industri rokok harus didukung oleh mesin-mesin dan peralatan yang memadai serta memiliki kehandalan yang 
cukup tinggi. Kehandalan mesin yang beroperasi di dalam pabrik rokok ditunjang oleh ketersediaan onderdil mesin yang berkualitas, yang sebagian besar masih harus didatangkan (diimpor) dari luar negeri.

Untuk menunjang operasional harian industri rokok, suku cadang mesin yang harus selalu tersedia dan siap digunakan adalah onderdil yang bersifat fast moving (sering diganti) dan removable (mudah dilakukan penggantian), salah satunya adalah Garniture. Garniture adalah sebuah spare part mesin rokok yang berbentuk seperti pita. Garniture Tape berfungsi untuk mengalirkan cigarette rod pada mesin Kedua bagian ini sangat rentan untuk rusak, baik itu putus, robek maupun longgar. Garniture juga memiliki banyak ukuran sesuai dengan jenis mesin rokok yang digunakan, namun yang sering digunakan adalah Garniture ukuran DIM 2810x19. Pembelian Garniture di impor dari sebuah perusahaan pembuat Garniture ternama di Itali yaitu Nasta Karena sebagian besar suku cadang masih harus diimpor dari luar negeri, maka kontinyuitas ketersediaan onderdil akan menjadi masalah ketika terjadi berbagai kondisi yang menyebabkan terjadinya fluktuasi harga yang tidak dapat diantisipasi dengan baik, baik oleh perusahaan rokok maupun oleh perusahaan penyedia suku cadang mesin rokok, sementara penggantian suku cadang dapat terjadi setiap saat.

CV. Bina Mekanik merupakan salah satu perusahaan yang berperan penting serta berpengalaman dalam menyuplai suku cadang mesin rokok. Sebagai perusahaan yang telah berpengalaman, perusahaan telah memiliki jaringan pemasok suku cadang yang berasal dari negara-negara eropa dan asia, diantaranya Italia, Swiss, Inggris dan China. Suku cadang tersebut diimpor dari negara asalnya ke Indonesia menggunakan transportasi laut yang memakan waktu yang cukup lama, sehingga terjadi beberapa masalah yang terkait dengan faktor ketidakpastian yang selanjutnya berpengaruh terhadap munculnya tambahan biaya atau penyusutan-penyusutan, yang ujung akhirnya akan berpengaruh terhadap fluktuasi harga jual. Faktor-faktor ketidakpastian yang berpengaruh tersebut antara lain adalah kurs mata uang, biaya transportasi dan logistik, faktor penyusutan, serta frekuensi transaksi dan pengiriman. Dari berbagai faktor penyumbang ketidakpastian tersebut, maka perlu ditentukan harga jual suku cadang yang jelas dan dapat terprediksi dengan baik agar kelanjutan operasional pabrik rokok maupun perusahaan penyedia suku cadang mesin rokok tidak terganggu.

\section{METODE PENELITIAN}

\subsection{Jenis Penelitian}

Jenis penelitian menggunakan eksploratif prediktif. Penelitian ini melakukan eksplorasi terhadap variabel berupa harga jual/pcs tiap bulannya yang selanjutnya digunakan untuk memprediksikan harga jual suku cadang mesin rokok impor pada CV. Bina Mekanik. Penelitian ini menggunakan data primer dan data sekunder, dimana data primer diperoleh dari responden yang berasal dari manajemen dan/atau pegawai CV. Bina Mekanik. Sedangkan data sekunder diperoleh dari beberapa sumber pendukung, yaitu dari informasi di internet, jurnal, artikel majalah di surat kabar, dan buku.

\subsection{Alur Penelitian}

Alur penelitian ini dibagi menjadi empat langkah inti. Langkah pertama memulai perencanan dengan studi literatur, merumuskan masalah dan tujuan serta membuat hipotesis. Langkah kedua mengumpulkan data dengan cara observasi,wawancara dan mencari refernsi baik dari buku maupun dari media elektronik. Langkah ketiga pengolahan dan analisa data dengan metode Backpropagation, Jaringan Syaraf Tiruan dibantu dengan tools Matlab 2012a. Langkah keempat pengujian instrument dengan memvalidasi hasil prediksi menggunakan MSE.

\subsection{Penelitian Terkait}

Penelitian tentang prediksi harga dengan menggunakan jaringan syaraf tiruan (JST) telah dilakukan oleh Indrawanto dkk. (2007) yang diterapkan untuk mengetahui perkiraan harga akarwangi. Penelitian tersebut menggunakan metodologi backpropagation dengan data fluktuasi berupa data deret waktu harga terna akarwangi dan harga akarwangi dalam setiap bulannya sejak Januari tahun 2000 sampai April 2006. Dalam penelitian tersebut, digunakan 3 fungsi aktivasi berupa sigmoid biner, sigmoid bipolar, dan purelin; 3 rentang nilai data transformasi, dan 4 macam neuron dengan 108 kombinasi. [1]

Volume kendaraan bertambah sejak 7 hari menjelang lebaran sampai 7 hari setelah lebaran tiap tahunnya terutama pada arah keluar dan masuk wilayah Jawa Tengah yang banyak menjadi tujuan mudik. Volume kendaraan saat arus mudik yang selalu meningkat inilah yang akan diteliti lebih lanjut dengan metode ANFIS agar dapat menjadi alternatif solusi langkah apa yang akan dilakukan di tahun selanjutnya agar pelayanan lalu lintas, kemacetan panjang dan angka kecelakaan berkurang. Dengan input parameter 
ANFIS yang digunakan yaitu pengclusteran hingga 5 cluster, epoch 100, error goal 0 diperoleh performa terbaik ANFIS dengan K-Means clustering yang terbagi menjadi 3 cluster, epoch terbaik sebesar 20 dengan RMSE Training terbaik sebesar 0,1198, RMSE Testing terbaik sebesar 0,0282 dan waktu proses tersingkat sebesar 0,0695. [2]

Sebuah penelitian untuk membangun suatu model dalam proses impor barang untuk mendapatkan laba yang optimal dari penjualan barang impor tersebut. Model ini meliputi prediksi harga jual kembali barang impor di pasar lokal dan pengoptimalan pembelian barang impor di pasar luar negeri. Proses prediksi harga jual kembali barang impor diperhitungkan menggunakan metode logika Fuzzy Tsukamoto. Input terdiri atas tiga barang yang berbeda dengan variabel yang akan diamati adalah permintaan barang, ketersediaan/stok barang dan harga pasaran di pasar lokal. Outputnya adalah perkiraan harga jual kembali dan keuntungan masing-masing barang impor. Proses pengoptimalan pembelian barang impor menggunakan metode program linier simplex. Variabel yang akan diperlukan antara lain perkiraan keuntungan masing-masing barang, modal yang tersedia, alokasi berat paket pengiriman, berat masingmasing barang, dan jumlah maksimum masing-masing barang yang akan dibeli. Hasil yang diperoleh dalam penelitian ini antara lain model prediksi harga jual kembali barang impor dan model pengoptimalan pembelian barang impor. Perhitungan dengan model ini dibandingkan dengan perhitungan nilai acak disimpulkan bahwa perhitungan dengan model ini memberikan nilai yang lebih optimal (Seniman, 2012). [3]

Pergerakan harga atau nilai mata uang asing selalu berubah-ubah dari waktu ke waktu sesuai dengan hukum permintaan dan penawaran. Perkembangan nilai yang fluktuatif tersebut menyebabkan valuta asing atau valas ini dalam perkembangannya juga digunakan sebagai instrumen investasi yang diperdagangkan. Mata uang Rupiah merupakan salah satu mata uang yang masuk ke dalam investasi perdagangan valas. Pergerakan kurs Rupiah yang cenderung mengalami fluktuatif menyebabkan pihak-pihak yang berkepentingan kesulitan dalam mengambil sebuah keputusan. Oleh karena itu dibutuhkan suatu kemampuan untuk mengetahui nilai tukar suatu mata uang di masa mendatang. Prediksi harga harian perdagangan suatu valas dapat ditentukan dengan menggunakan pendekatan jaringan saraf tiruan (JST). Backpropagation merupakan salah satu metode JST yang dapat digunakan dengan baik dalam bidang prediksi. Berdasarkan hasil analisis penelitian menggunakan 200 data training dan 10 data testing, penggunaan 9 Neuron hidden layer serta pemilihan nilai Momentum sebesar 0,1 dan Learning rate sebesar 0,7 menghasilkan nilai MSE yang paling kecil apabila dibandingkan dengan arsitektur jaringan lainnya yaitu MSE high sebesar 0.28726788134455, MSE low sebesar 0.23733577234585, dan MSE close sebesar 0.30996627875935 (Reza Subintara, 2015). [4]

Jumlah NEM yang tinggi ternyata tidak menjamin lulusan berprestasi akademik tinggi, maka pada penelitian ini akan diuji korelasi antara komposisi NEM SLTA dengan indeks prestasi kumulatif lulusan PSTI-X dengan pendekatan jaringan syaraf tiruan umpan-maju perambatan-balik (JST-PB). Ini diharapkan dapat dijadikan sebagai pedoman untuk menentukan komposisi nilai NEM SLTA yang tepat dalam seleksi PMB, khususnya yang lewat jalur fellowship. Hasil penelitian menunjukkan bahwa JST-PB hanya memiliki tingkat keberhasilan 64\% dalam memetakan komposisi NEM dan prestasi akademik lulusan. Hasil ini memperkuat hasil penelitian sebelumnya dengan menggunakan analisis korelasi dan regresi linier ganda bahwa NEM tidak dapat dijadikan sebagai acuan mutlak dalam sistem seleksi PMB. Hasil penelitian ini memberikan rekomendasi bahwa PSTI-X perlu mengkaji kembali sistem PMBnya, khususnya yang melalui jalur fellowship.[5]

Penelitian ini bertujuan umtuk menentukan rancangan arsitektur jaringan syaraf tiruan backpropagation terbaik dan meramalkan jumlah permintaan produk v-belt AJGG B-65. Penelitian ini menggunakan metode Jaringan Syaraf Tiruan (JST) dengan faktor terkait yaitu hasil penjualan, harga dan stok barang jadi. Pengolahan JST menggunakan software MATLAB. Penerapan metode JST di PT.XYZ menggunakan algoritma Backpropagation. Arsitektur jaringan syaraf tiruan yang digunakan yaitu 3 input layer, 1 output layer, dan 1 hidden layer serta fungsi aktivasi yang digunakan logsig dan purelin. Logsig untuk hidden layer dan purelin untuk output layer. Rancangan arsitektur jaringan syaraf tiruan terbaik untuk peramalan permintaan v-belt AJGG B-65 adalah jaringan multi layer feedforward dengan struktur neuron 20-1 dengan 1 (satu) hidden layer, learning rate (lr) yang digunakan 0,1 dan momentum constant (mc) 0,2. Nilai Mean Square Error (MSE) pelatihan jaringan sebesar 0,001 Nilai MAPE pengujian data sebesar $5,7134 \%$. [6].

\section{HASIL DAN PEMBAHASAN}

Data diperoleh dari observasi dan wawancara terhadap owner maupun karyawan CV. Bina Mekanik. Data disusun sesuai harga/pes pembelian Garniture tiap bulan selama 5 tahun, mulai tahun 2011 hingga tahun 2016. HPP/pcs diperoleh dari harga asli barang impor tersebut dari NASTA srl Italy di akumulasikan dengan kurs mata uang Euro. Dari Italy, barang dikirim menuju Singapore dengan biaya pengiriman 
menggunakan mata uang Euro. Setelah tiba di Singapore pengiriman dilanjutkan menuju Jakarta dengan biaya pengiriman yang disesuaikan dengan mata uang Dolar Singapore. Pengiriman akan dilanjutkan dari Jakarta menuju Kudus dengan biaya menggunakan mata uang Rupiah. Namun dalam pendataannya semua dijumlah menggunakan mata uang Rupiah hingga ditentukan harga jual/pcs adalah harga pokok pembelian (HPP) ditambah dengan profit 25\% dari HPP serta biaya logistic atau pengiriman. Berikut ini adalah data asli harga penjualan/pcs Garniture pada tabel 1.

Tabel 1. Data time series harga jual garniture

\begin{tabular}{ccc}
\hline Tahun & Bulan & Harga Jual/pcs \\
\hline & Januari & Rp 151.369.51 \\
& Februari & Rp 150.682.82 \\
& Maret & Rp 150.590.86 \\
& April & Rp 149.553.25 \\
& Mei & Rp 148.813.90 \\
& Juni & Rp 135.702.47 \\
2011 & Juli & Rp 129.360.33 \\
& Agustus & Rp 129.921.10 \\
& September & Rp 149.148.08 \\
& Oktober & Rp 147.980.70 \\
& November & Rp 130.928.66 \\
& Desember & Rp 129.761.68 \\
& Januari & Rp 126.891.31 \\
2012 & Februari & Rp 130.650.82 \\
& Maret & Rp 128.848.22 \\
& ... & \\
& Desember & Rp 133.472.66 \\
\hline
\end{tabular}

\subsection{Analisis Masalah}

CV. Bina Mekanik mengimpor suku cadang mesin rokok ke Indonesia menggunakan transportasi laut yang memakan waktu yang cukup lama, sehingga terjadi beberapa masalah yang terkait dengan faktor ketidakpastian yang selanjutnya berpengaruh terhadap munculnya tambahan biaya atau penyusutanpenyusutan, yang akhirnya berpengaruh terhadap fluktuasi harga jual. Harga suku cadang menjadi tidak menentu karena beberapa factor ketidakpastian yang sangat berpengaruh misalnya kurs mata uang dan biaya logistik. Dari berbagai faktor penyumbang ketidakpastian tersebut, maka perlu ditentukan harga jual suku cadang yang jelas dan dapat terprediksi dengan baik agar kelanjutan operasional pabrik rokok maupun perusahaan penyedia suku cadang mesin rokok tidak terganggu. Prediksi ini menggunakan algoritma Backpropagation yaitu salah satu algoritma Jaringan Sayaraf Tiruan yang cukup baik untuk menghasilkan prediksi harga jual suku cadang yang akurat.

\subsection{Pembahasan}

\subsubsection{Preprocessing Data}

Tahap awal pembahasan untuk memecahkan masalah harga Garniture yang dilakukan dengan preprocessing data terlebih dahulu untuk mengatasi data-data yang masih kosong atau missing. Preprocessing data menggunakan rumus atau persamaan Normalisasi pada persamaan 1.[7] Sebagai data sample digunakan sekitar 15 record dari 60 record, dapat dilihat pada tabel 2.

$x$ normalisasi $=\frac{0,8(x-x \min )}{(x \max -x \min )}+0,1$ 
Tabel 2. Hasil normalisasi data asli

\begin{tabular}{|c|c|c|c|}
\hline Tahun & Bulan & $\begin{array}{c}\text { Harga } \\
\text { Jual/pcs }\end{array}$ & $X$ normalisasi \\
\hline \multirow{11}{*}{2011} & Januari & Rp 151.369.51 & 0.539078319 \\
\hline & Februari & Rp 150.682.82 & 0.52676088 \\
\hline & Maret & Rp 150.590.86 & 0.525111299 \\
\hline & April & Rp 149.553.25 & 0.506499159 \\
\hline & Mei & $\operatorname{Rp} 148.813 .90$ & 0.493237048 \\
\hline & Juni & Rp 135.702 .47 & 0.258050436 \\
\hline & Juli & Rp 129.360 .33 & 0.144288073 \\
\hline & Agustus & Rp 129.921.10 & 0.154346876 \\
\hline & September & Rp 149.148.08 & 0.499231322 \\
\hline & Oktober & Rp 147.980.70 & 0.478291422 \\
\hline & November & Rp 130.928.66 & 0.172420061 \\
\hline \multirow{4}{*}{2012} & Desember & Rp 129.761 .68 & 0.151487325 \\
\hline & Januari & Rp 126.891.31 & 0.1 \\
\hline & Februari & $\mathrm{Rp} 130.650 .82$ & 0.167436298 \\
\hline & Maret & Rp 128.848 .22 & 0.135102111 \\
\hline $\begin{array}{c}\ldots \\
2016\end{array}$ & $\begin{array}{c}\cdots \\
\text { Desember }\end{array}$ & Rp 133.472.66 & 0.218053104 \\
\hline
\end{tabular}

Hasil normalisasi data asli dari data pertama hingga 60 akan bernilai atau berskala 0,1 hingga 0,9 sesuai dengan persamaaan yang digunakan di atas.

\subsubsection{Pembentukan Variabel Multivariate}

Proses training dan testing yang akan dilakukan memerlukan proses perubahan dari variabel univariate yang sudah di normalisasi sebelumnya menjadi variabel multivariate. Proses perubahan variabel dilakukan agar hasil output prediksi yang diperoleh lebih baik dan akurat. Data training seperti pada tabel 3 .

Tabel 3. Data Training

\begin{tabular}{llll}
\hline \multicolumn{1}{c}{$\boldsymbol{x} \boldsymbol{1}$} & \multicolumn{1}{c}{$\boldsymbol{x} \boldsymbol{2}$} & $\ldots$ & \multicolumn{1}{c}{$\boldsymbol{x \boldsymbol { 2 4 }}$} \\
\hline 0.539078319 & 0.52676088 & $\ldots$ & 0.155129181 \\
0.52676088 & 0.525111299 & $\ldots$ & 0.210870767 \\
0.525111299 & 0.506499159 & $\ldots$ & 0.268356066 \\
0.506499159 & 0.493237048 & $\ldots$ & 0.230564736 \\
0.493237048 & 0.258050436 & $\ldots$ & 0.118207075 \\
0.258050436 & 0.144288073 & $\ldots$ & 0.202627038 \\
0.144288073 & 0.154346876 & $\ldots$ & 0.155752538 \\
0.154346876 & 0.499231322 & $\ldots$ & 0.219816052 \\
0.499231322 & 0.478291422 & $\ldots$ & 0.504102934 \\
0.478291422 & 0.172420061 & $\ldots$ & 0.505862402 \\
0.172420061 & 0.151487325 & $\ldots$ & 0.229084053 \\
0.151487325 & 0.1 & $\ldots$ & 0.231066859 \\
0.1 & 0.167436298 & $\ldots$ & 0.208878968 \\
0.167436298 & 0.135102111 & $\ldots$ & 0.206365399 \\
0.135102111 & 0.587490325 & $\ldots$ & 0.154825377 \\
0.587490325 & 0.621018255 & $\ldots$ & 0.152139172 \\
0.621018255 & 0.183752812 & $\ldots$ & 0.152247701 \\
0.183752812 & 0.14551664 & $\ldots$ & 0.864875685 \\
0.14551664 & 0.13344845 & $\ldots$ & 0.14969648 \\
0.13344845 & 0.19378832 & $\ldots$ & 0.214099558 \\
0.19378832 & 0.147736767 & $\ldots$ & 0.814928321 \\
0.147736767 & 0.157495679 & $\ldots$ & 0.214526624 \\
0.157495679 & 0.155129181 & $\ldots$ & 0.215334164 \\
0.155129181 & 0.210870767 & $\ldots$ & 0.214102565 \\
\hline
\end{tabular}

\subsubsection{Proses Pengolahan Data}

Data multivariate yang sudah dibagi menjadi inputan training dan inputan testing selanjutnya akan diolah dengan algoritma Backpropagation dari Jaringan Syaraf Tiruan. Langkah-langkah algoritma Backpropagation adalah sebagai berikut [8] : 
a. Langkah 1

Inisialisasi bobot. (sebaiknya diatur pada nilai acak kecil) selama kondisi berhenti belum dicapai, maka lakukan langkah ke-2 hingga langkah ke-9.

b. Langkah 2

Untuk setiap pasangan pola pelatihan lakukan langkah ke-3 sampai langkah ke-8

c. Langkah 3

Tiap unit masukan $(x i, i=1, \ldots, n)$ menerima sinyal xi dan menghantarkan sinyal ini ke semua unit lapisan di atasnya (unit tersembunyi),

d. Langkah 4

Setiap unit tersembunyi $(x i, i=1, \ldots, p)$ jumlahkan bobot sinyal masukannya dengan persamaan 2 dan 3,

$$
\begin{aligned}
& z_{-} i n_{j}=v_{0 j}+\sum_{i=1}^{n} x_{i} v_{i j} \\
& z=f(x)=\frac{1}{1+e^{-z_{-} i n}}
\end{aligned}
$$

e. Langkah 5

Langkah 5: Tiap unit keluaran $(y k, k=1, \ldots, m)$ jumlahkan bobot sinyal masukannya dengan persamaan 4 dan 5 ,

$$
\begin{aligned}
& y=\frac{1}{1+e^{-y_{-} i n}} \\
& y_{-} i n_{k}=w_{0 k}+\sum_{j=1}^{p} z_{j} w_{j k}
\end{aligned}
$$

f. Langkah 6

Tiap unit keluaran $(y k, k=1, \ldots, m)$ menerima pola target yang saling berhubungan pada masukan pola pelatihan, hitung kesalahan informasinya dengan persamaan 6 ,

$\delta_{\mathrm{k}}=\left(\mathrm{t}_{\mathrm{k}}-\mathrm{y}_{\mathrm{k}}\right) \mathrm{f}^{\prime}\left(\mathrm{y} \_\right.$net $\left.\mathrm{k}_{\mathrm{k}}\right)=\left(\mathrm{t}_{\mathrm{k}}-\mathrm{y}_{\mathrm{k}}\right) \mathrm{y}_{\mathrm{k}}\left(1-\mathrm{y}_{\mathrm{k}}\right)$

hitung koreksi bobot menggunakan persamaan 7 dan 8 (digunakan untuk memperbaharui $\mathrm{w}_{\mathrm{jk}}$ nantinya),

$\Delta \mathrm{w}_{\mathrm{jk}}=\alpha \delta_{\mathrm{k}} \mathrm{Z}_{\mathrm{j}}$

$\Delta \mathrm{w}_{\mathrm{ok}}=\alpha \delta_{\mathrm{k}}$

Hitung koreksi biasnya (digunakan untuk memperbaharui $\mathrm{w}_{\mathrm{ok}}$ ), dan kirimkan $\delta k$ ke unit-unit pada lapisan dibawahnya

g. Langkah 7

Setiap unit lapisan tersembunyi $(z j, j=1 \ldots p)$ jumlahkan hasil perubahan masukannya (dari unitunit lapisan diatasnya) dengan persamaan 9 ,

$$
\delta_{-} i n_{j}=\sum_{k=1}^{m} \delta_{k} w_{j k}
$$

Kalikan dengan turunan fungsi aktivasinya untuk menghitung informasi kesalahannya,

$$
\delta_{j}=\delta_{-} i n_{j} f^{\prime}\left(\delta_{-} i n_{j}\right)
$$

Hitung koreksi bobotnya (digunakan untuk memperbaharui voj nanti) menggunakan persamaan 11 dan 12 ,

$$
\Delta \mathrm{V}_{\mathrm{ji}}=\alpha \delta_{\mathrm{j}} \mathrm{x}_{\mathrm{j}}
$$




$$
\Delta \mathrm{V}_{\mathrm{jo}}=\alpha \delta_{\mathrm{j}}
$$

h. Langkah 8

Masing-masing unit output ( $\left.\mathrm{y}_{\mathrm{k}}, \mathrm{k}=1,2,3, \ldots \mathrm{m}\right)$ dilakukan pengupdetan bias dan bobotnya $(\mathrm{j}=1,2,3, \ldots, \mathrm{p})$ sehingga menghasilkan bobot dan bias baru.

$$
\mathrm{W}_{\mathrm{jk}}(\mathrm{baru})=\mathrm{W}_{\mathrm{jk}}(\text { lama })+\Delta \mathrm{W}_{\mathrm{jk}}
$$

Demikian juga untuk setiap unit tersembunyi mulai dari unit ke-1 sampai dengan unit ke-p dilakukan pengupdetan bobot dan bias:

$$
\left.\mathrm{V}_{\mathrm{ji}}(\text { baru })=\mathrm{V}_{\mathrm{ji}}(\text { lama })+\Delta \mathrm{V}_{\mathrm{ij}}\right)
$$

i. Langkah 9 : Uji kondisi behenti (akhir iterasi)

Untuk membantu proses pengolahan data dengan algoritma Backpropagation, penelitian ini menggunakan software atau tools Matlab. Gambar 1 merupakan hasil pengolahan data training:

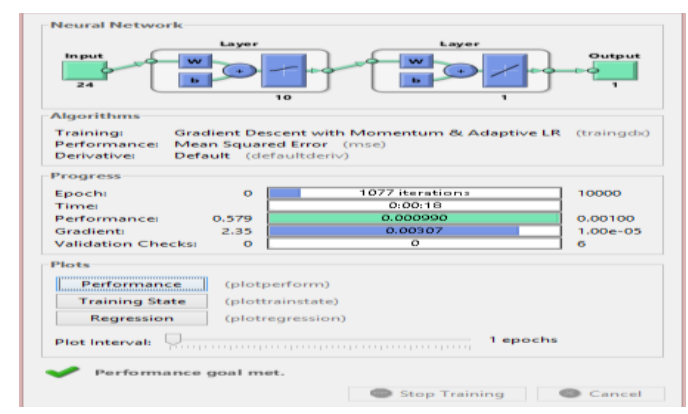

Gambar 1. Hasil Training Bakpropagation

Terlihat pada gambar 1 alur Backpropagation 24 inputan dengan 10 neuron hidden layer dan 1 keluaran. Performance dihitung dengan MSE, kemudian perhitungan berhenti pada iterasi ke-1077 dengan penyediaan iterasi maksimal sebanyak 10000 iterasi. Selanjutnya pada gambar 2 adalah hasil regression perbandingan dari output dari JST dan target asli.

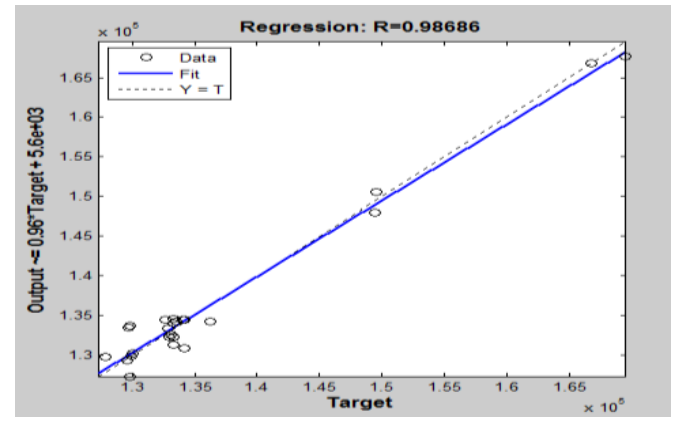

Gambar 2. Hasil Data Regresi

Garis putus-putus yang berarti bahwa $\mathrm{Y}=\mathrm{T}$ atau output hasil Bacpropagation dengan target sama. Pada gambar 2 nilai regresi 0.98686 yang menyatakan garis biru dan data sudah berada pada garis putusputus yang memiliki arti output hampir sama dengan target. Sedangkan pada gambar 4 adalah hasil training dan keluaran JST 


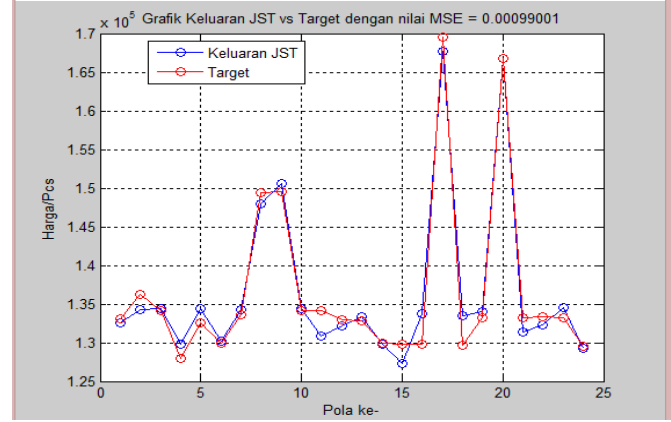

Gambar 3. Hasil Training Target dan Keluaran JST

Hasil output diperkirakan sudah sesuai dengan target seperti gambar 4. Hasil training yang cukup baik dengan nilai MSE 0,00099001. Proses training yang cukup baik tersebut akan digunakan untuk proses testing.

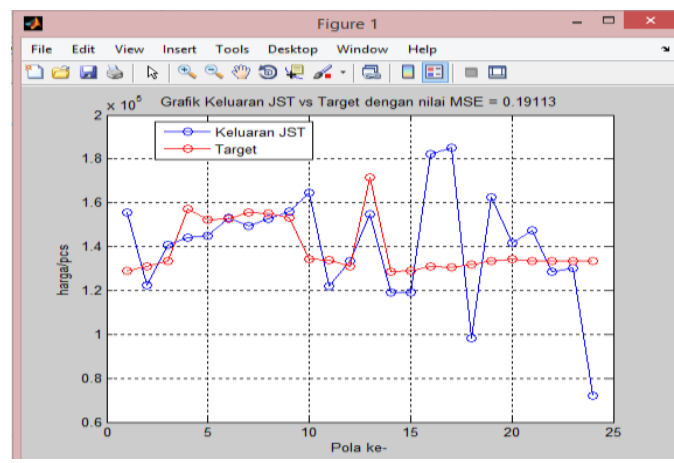

Gambar 4. Hasil Testing

Hasil testing yang cukup baik dengan nilai MSE 0,19113 memperlihatkan bahwa antara keluaran JST dengan target memang berbeda. Perbedaan keluaran JST ini merupakan hasil prediksi harga jual suku cadang mesin rokok Garniture untuk bulan dan tahun berikutnya. Tabel 4 adalah hasil perbandingan antara target data testing dengan keluaran JST yang berupa hasil prediksi:

Tabel 4. Perbandingan Testing Target dan Keluaran JST

\begin{tabular}{cc}
\hline Target & Keluaran JST \\
\hline 128993.131840909 & 155760.5063 \\
130998.262483333 & 122343.0017 \\
133441.742250000 & 140775.5375 \\
157140.006834746 & 143928.162 \\
152169.131931818 & 145029.1023 \\
152922.556200000 & 153299.3231 \\
155559.858166667 & 149284.7175 \\
155013.610472222 & 152918.8213 \\
153009.723150000 & 156058.0438 \\
134287.842390000 & 164451.3105 \\
133965.911958333 & 121974.1082 \\
130909.383716667 & 133659.2829 \\
171490.547029560 & 154836.3093 \\
128487.552022727 & 119157.863 \\
129057.931781250 & 119119.6316 \\
130966.021879032 & 182375.629 \\
130817.024350000 & 184978.344 \\
131642.852550000 & 98269.02085 \\
133392.432110000 & 162670.3189 \\
134145.971833333 & 141639.2522 \\
133549.391830000 & 147508.9756 \\
133491.839268519 & 128462.9687 \\
133480.661821429 & 130187.9301 \\
133472.660214286 & 72040.73448 \\
\hline
\end{tabular}




\subsubsection{Proses Validasi Data}

Proses validasi data merupakan proses paling akhir dalam penelitian ini. Proses validasi akan memperlihatkan seberapa akurat hasil prediksi menggunakan algoritma Backpropagation dengan data pada tabel 4. MSE (Mean Square Error) pada persamaan 15 yang digunakan untuk membandingkan antara data asli dengan data hasil output prediksi harga jual suku cadang mesin rokok.

$\operatorname{MSE}=\frac{\sum\left(y_{i}-\hat{y}_{i}\right)^{2}}{n}[9]$

Maka dengan menjumlahkan selisih antara data asli dengan data hasil output dari perhitungan menggunakan tools Matlab, diperoleh hasil MSE untuk menentukan akurasi perhitungan dengan bantuan Matlab sebagai berikut:

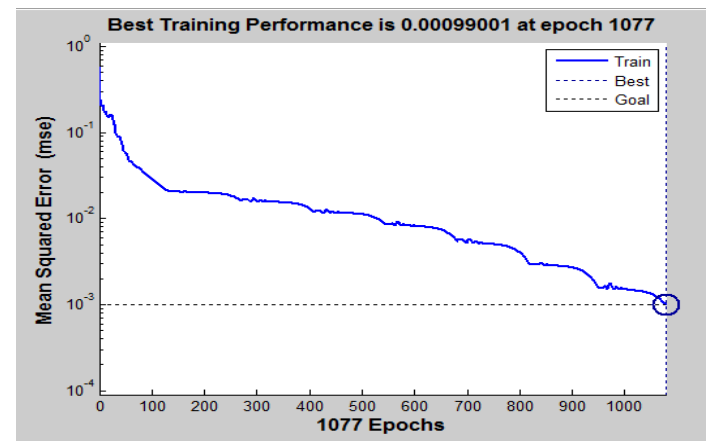

Gambar 5. Hasil Validasi Output Training

Hasil MSE dari proses training menunjukkan nilai 0,00099001 yang memiliki arti selisih atau error antara target asli dengan hasil output sangat kecil. Sedangkan proses testing juga menunjukkan nilai MSE yang cukup kecil sebesar 0,19113 .

\subsection{Hasil Penelitian}

Seluruh rangkaian penelitian yang sudah dilaksanakan menghasilkan prediksi harga jual suku cadang mesin rokok Garniture ukuran DIM 2810x19 pada bulan dan tahun berikutnya. Sesuai dengan hasil training dan testing hasil prediksi yang dihasilkan pada bulan dan tahun berikutnya seperti tabel 5:

Tabel 5. Hasil prediksi tahun 2017/2018

\begin{tabular}{ccc}
\hline Tahun & Bulan & Prediksi Harga Jual/pcs \\
\hline & Januari & Rp155.760.51 \\
Februari & Rp122.343.00 \\
Maret & Rp140.775.54 \\
& April & Rp143.928.16 \\
Mei & Rp145.029.10 \\
& Juni & Rp153.299.32 \\
& Juli & Rp149.284.72 \\
Agustus & Rp152.918.82 \\
& September & Rp156.058.04 \\
Oktober & Rp164.451.31 \\
& November & Rp121.974.11 \\
& Desember & Rp133.659.28 \\
& Januari & Rp154.836.31 \\
& Februari & Rp119.157.86 \\
& Maret & Rp119.119.63 \\
& April & Rp182.375.63 \\
& Mei & Rp184.978.34 \\
& Juni & Rp98.269.02 \\
& Juli & Rp162.670.32 \\
& Agustus & Rp141.639.25 \\
& September & Rp147.508.98 \\
& Oktober & Rp128.462.97 \\
November & Rp130.187.93 \\
Desember & Rp72.040.73 \\
\hline & & \\
& &
\end{tabular}


Dari hasil tersebut dpata dianalisa bahwa harga jual suku cadang mesin rokok masih stabil dengan kenaikan dan penurunan harga yang signifikan selama 2 tahun kedepan. Dengan prediksi ini diharapkan dapat membantu CV. Bina Mekanik agar lebih mudah mengontrol harga jual suku cadang Garniture.

\section{PENUTUP}

\subsection{Kesimpulan}

Terkait dengan hasil proses training dan testing yang telah dilaksanakan menggunakan algoritma Backpropagation dari Jaringan Syaraf Tiruan dengan 24 inputan, 10 hidden layer, learning rate 0,1 dan 1 output, maka diperoleh nilai error atau MSE yang cukup baik pada proses training sebesar 0,00099001 dan MSE pada proses testing sebesar 0,19113. Proses prediksi tersebut menghasilkan harga Garniture untuk tiap bulannya di tahun 2017 dan 2018. Bulan Januari prediksi harga Graniture berada pada kisaran harga Rp 155.760.51, analisanya bahwa harga Garniture yang semakin meningkat tersebut dapat direkomendasikan pada CV. Bina Mekanik untuk mewaspadai munculnya tambahan biaya atau penyusutan-penyusutan, yang pada akhirnya akan berpengaruh terhadap fluktuasi harga jual.

\subsection{Rekomendasi}

Berdasarkan kesimpulan penelitian rekomendasi yang perlu di berikan penulis adalah:

a. Perlu adanya perbaruan terhadap hasil prediksi yang sudah ada saat ini dengan menggunakan metode lain yang mungkin lebih efektif dan efisien.

b. Diperlukan adanya penelitian mengenai prediksi terhadap keuntungan dari hasil penjualan Garniture.

\section{DAFTAR PUSTAKA}

[1] Indrawanto, C. Eriyatin, Fauzi, A. M., Machfud, Sukardi, dan Soetrisno, N. "Perkiraan Harga Akarwangi: Aplikasi Metode Jaringan Syaraf Tiruan”. Jurnal Littri 13 (1), 14-20, 2007. http://ejurnal.litbang.pertanian.go.id/index.php/jptip/article/view/2829/2463

[2] Evanita, Noersasongko, Edi., "Prediksi Volume Lalu Lintas Angkutan Lebaran pada Wilayah Jawa Tengah dengan Metode K-Means Clustering untuk Adaptive Neuro Fuzzy Inference System

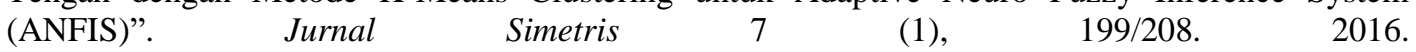
http://jurnal.umk.ac.id/index.php/simet/article/view/505

[3] Seniman. "Logika Fuzzy dan Program Linier untuk Pengoptimalan Perolehan Laba Dalam Impor Barang”. Universitas Sumatera Utara, Medan, 2012.

[4] Subintara, Reza. "Prediksi Pergerakan Harga Harian Nilai Tukar Rupiah (IDR) Terhadap Dollar Amerika (USD) Menggunakan Metode Jaringan Saraf Tiruan Backpropagation”. Universitas Dian Nuswantoro, 2016.

[5] Nuraeni, Y. "Penerapan Jaringan Syaraf Tiruan untuk Mengukur Tingkat Korelasi antara NEM dengan IPK Kelulusan Mahasiswa”. Telkomnika 7 (3), 195-200. 2009. http://dx.doi.org/10.12928/telkomnika.v7i3.594

[6] [6] Febriana, M. Arina, F., dan Ekawati, R. "Peramalan Jumlah Permintaan Produksi Menggunakan Metode Jaringan Syaraf Tiruan (JST) Backpropagation”. Jurnal Teknik Industri 1(2), 174-179, 2013. http://jurnal.untirta.ac.id/index.php/jti/article/view/140

[7] Sidauruk, Jenni. "Implementasi Jaringan Syaraf Tiruan Untuk Memprediksi Merek Kosmetik Yang Paling Diminati Konsumen Menggunakan Metode Backpropogation”. Jurnal Pelita Informatika 16 (3), 288-293, 2017. http://ejurnal.stmik-budidarma.ac.id/index.php/pelita/article/view/444

[8] Jong, Jek Siang. (2005). Jaringan Syaraf Tiruan dan Pemrogramannya Menggunakan MATLAB. Penerbit Andi, Yogyakarta.

[9] Prasetyo, Eko. (2012). Data Mining Mengolah Data Menggunakan Matlab. Penerbit Andi, Yogyakarta. 